\title{
Forestry Research Advisory Council of Canada Annual Report for 1994
}

\section{Preamble}

The following report, written in December 1994, describes the activities of the Forestry Research Advisory Council of Canada (FRACC) in 1994. As a result of the February 1995 federal budget, considerable change will take place in the Canadian Forest Service (CFS) in particular and in forestry research in Canada in general. The new terms of reference and workplan highlighted in the report will therefore not be implemented as planned. FRACC is re-examining its role in the new environment for CFS and has offered advice to Natural Resources Canada regarding advisory mechanisms to guide CFS in this period of change.

\section{Annual Report for 1994 \\ Introduction}

FRACC (membership listed in Appendix I) held three meetings in 1994, in addition to a workshop on landscape management held in conjunction with the fall meeting, to help identify emerging research needs in this area.

FRACC's deliberations were concerned mainly with two related issues, one procedural, the other more strategic:

1. A review of its terms of reference and the development of a workplan for 1995.

2. Examination of the impact of various federal reviews on forestry research in Canada.

\section{Terms of Reference and Workplan}

FRACC's new terms of reference, as approved by the Assistant Deputy Minister for the Canadian Forest Service (CFS), are found in Appendix II. They highlight FRACC's responsibility for providing advice on strategic issues and for identification of emerging needs for forest research in Canada. In these changing times, it is important for CFS and other players in the R\&D scene to work together to maximize the returns on the modest resources invested in forest research in Canada.

FRACC's membership will be renewed in 1995, as several members have completed their terms. FRACC members will be chosen on the basis of the new terms of reference. FRACC needs strategic thinkers who understand research and believe in research, who can advise on needs, priorities, and issues and who have the time and energy to devote to FRACC's activities. New issues emerge at a much faster pace than previously. Therefore, it will be important for CFS to rotate the membership as specified in the terms of reference, with three-year terms, renewable once.

FRACC believes that it is extremely important for all stakeholders in the forest research enterprise to look at new ways of working together to ensure that research resources are deployed in the most efficient manner. Its new terms of reference have provided FRACC with an opportunity to develop a workplan that will respond to expectations of CFS in particular and of the forest sector in general. FRACC's workplan for 1995 has been developed in this spirit. The tasks are grouped under three major headings:

- Value of research and funding (overall state of research).

- Research needs and priorities (major trends and issues).

- Advice on CFS plans, internal and external functions (including partnerships).

The plan culminates in the presentation of a position paper on forestry research in Canada to the Canadian Council of Forest Ministers (CCFM). A summary of the plan is presented in Table 1.

\section{Impact of Various Federal Reviews on Forestry Research in Canada}

As part of the consultation process for the federal science and technology review, the Chair of FRACC sent a brief to the National Advisory Board on Science and Technology on behalf of the

Table 1. Forestry Research Advisory Council of Canada (FRACC) 1995 Workplan

\begin{tabular}{ll}
\hline Task & Brief description \\
\hline Value of research &
\end{tabular}

Inventory of forest research

Criteria and indicators to assess the state of forest resources

Federal S\&T expenditures in forestry

Needs and priorities Priority Framework

Emerging Issues

Review of Strategic Plan

Paper on technology transfer

CFS partnerships

The state of forestry research in Canada
To update and improve the inventory of forestry research in Canada being compiled by FRACC

To analyze existing information on Helsink and Montreal processes and synthesize it to help identify research priorities

To analyze federal expenditures on forestry research, on a program by program basis, with emphasis on the source of funding, i.e., CFS base budget or other sources such as Green Plan Funding or Forest Resource Development Agreements

Various groups will be asked for the methodology they use to identify research priorities (e.g. criteria, consultation process) These will be analyzed, and FRACC will adopt the most promising approach to recommend research priorities

FRACC has used a workshop approach to help identify emerging issues in the area of landscape management. This approach will be used on a biennial basis. Tentatively, a workshop on biodiversity will be held in 1996. In 1995, provincial councils will be asked for a list of emerging issues, which FRACC will analyze and synthesize

CFS Strategic Plan has been completed in 1994

Since considerable work has already been done internally by CFS in this area, FRACC asked CFS for a phase 1 report, summarizing current status and highlighting results of audit reports. FRACC will consider the report and decide how to proceed for phase 2 . There may be a need for a survey of those on the receiving end and/or of provincial FRACs before a phase 2 report is drafted

FRACC asked CFS for a report on partnerships

All of the above tasks culminate in the preparation of a position paper on the state of forestry research in Canada to be presented to CCFM 
Council. This brief highlights the importance of the forest sector to the economy, the need for accelerated research on the management of the resource, and the major role played by the federal government, mainly through CFS, in the performance and support of research. (The brief is found in Appendix III.) Individual FRACC members also participated in the local and regional consultations of the science and technology review.

At its fall meeting, FRACC learned that the program review undertaken by the federal government would most likely lead to major cuts in most federal departments, including Natural Resources Canada and CFS. In addition to this expected downsizing, Forest Resource Development Agreements (FRDAs) are coming to an end (as are several other sectoral agreements). As a result, the picture is not rosy, and creative solutions will be required to ensure that decreasing research resources are allocated in the most productive manner. CFS is a major player in the R\&D scene, and changes will affect the whole forest sector.

FRACC expresses concern that the vertical program review was not linked to the more horizontal science and technology review. Although members agree that deficit cutting must be a priority and accept that CFS has to contribute its share, they firmly believe that science and technology should also be a priority, especially R\&D in support of a sector that contributes so much to the health of the economy. CFS's main mission is R\&D. Therefore, cuts to CFS mean cuts to R\&D. Other departments may be able to choose between R\&D and other areas of activity. This is not the case for CFS and other researchintensive federal organizations.

In 1995, FRACC will monitor CFS's fiscal situation very closely, and advise CFS on how best to adjust to the new environment. There is no question that new partnerships will have to be developed and that cooperation and collaboration with industry and between levels of government will have to be enhanced. In this regard, in response to a request of the Forest Sector Advisory Committee (FSAC), FRACC will soon complete a paper which suggests possible approaches to the joint support of forestry research by the various stakeholders on a provincial or regional basis.

\section{Emerging Research Needs}

A commitment was made to CCFM in 1993 that FRACC would hold biennial workshops as a means of highlighting research needs in emerging areas. The first of these workshops was on the topic of landscape management. The workshop started in the evening of November 23 with a presentation by Dr. Louis LaPierre from the University of Moncton. It resumed the following day, with an introduction by Dr. Ole Hendrickson from CFS and four presentations: by Dr. Louis Bélanger from Laval University, Dr. Richard Sims of CFS (Sault Ste. Marie), Dr. Steven Garman from the University of Oregon, and Dr. Richard Page from the British Columbia Ministry of Forests. A summary of the presentations and of the ensuing discussions is found in Appendix IV. The Chair concluded the workshop by asking members to list issues they identified as a result of the workshop. The resulting list follows:

- Importance of the people dimension and of public information (public forums are a functional means of identifying priorities).

- Need for adaptive management as the needs of society and ecosystem functioning are more precisely defined.

- Decisions to be made about which models to adopt as being the most useful to shed light on ecosystem functioning.

- Research as a tool for forest managers.

- Importance of long-term experiments, such as model forests, to provide multidisciplinary input within a framework people are able to relate to.

- Finding the right balance between short-term (e.g. helping managers) and long-term (e.g. model forests, fundamental research) considerations.

- Information overload is now a real problem; there is a need for better management and use of information.

FRACC members found this first workshop very useful as a means of obtaining a comprehensive overview of a complex topic with national and international ramifications.

\section{Appendix I. Membership List — March 1995}

\section{Chair}

Mr. Michael R. Innes

Manager of Forestry, Abitibi-Price Inc., 207 Queen's Quay West, Box 102, Toronto, ON, M5J 2P5. Tel: (416) 203-5042, Fax: (416) 203-5045

\section{Provincial Representation}

Dr. Ted E. Baker

Research Branch, Ministry of Forests, 31 Bastion Square, Victoria, BC, V8W 3E7. Tel: (604) 387-6720, Fax: (604) 387-0046

$\mathrm{D}^{\mathrm{r}}$ Jean-Guy Davidson

Chef, Service de la recherche appliquée, Ministère des Ressources naturelles, 2700, rue Einstein, Bloc B.1.190, Sainte-Foy, QC, G1P 3W8. Tel: (418) 643-7994, Fax: (418) 643-2165

\section{Mr. Murray Little}

Director, Forestry Branch, Saskatchewan Environment and Resource Management, Box 3003, Prince Albert, SK, S6V 6G1. Tel: (306) 953-2486, Fax: (306) 953-2360

\section{Dr. Jim MacLean}

Ministry of Natural Resources, P.O. Box 5000, Maple, ON, L6A 1S9. Tel: (905) 832-7260, Fax: (905) 832-7172

\section{Industrial Representation}

M. Jean Bérard

11480, rue Pasteur, Montréal, QC, H3M 2P1. Tél: (514) 334-7810, Téléc: (514) 334-6685

Mr. Gerald Lapointe

Canadian Pulp and Paper Association, 19th Floor, 1155 Metcalfe Street, Montreal, QC, H3B 4T6. Tel: (514) 866-6621, Fax: (514) 866-3035

Mr. Ian Taviss

Research Coordinator, New Brunswick Executive Research Council, Hugh John Flemming Forestry Centre, Fredericton, NB, E3B 6H6. Tel: (506) 452-6932, Fax: (506) 450-3128

\section{Professional Representation}

Mr. W.J. Brown

General Manager, Algonquin Forestry Authority, 222 Main Street 
West, Huntsville, ON, P0A 1K0. Tel: (705) 789-9647, Fax: (705) 789-3353

\section{University Representation}

Dr. Peter J. Murphy

Department of Forest Science, Faculty of Agriculture \& Forestry, University of Alberta, 751 General Services Building, Edmonton, AB, T6G 2H1. Tel: (403) 492-2359, Fax: (403) 492-4323

Dr Gilles Frisque

Directeur, Centre multirégional de recherche forestière, Institut Armand-Frappier, 531, boulevard des Prairies, Case postale 100, Laval, QC, H7N 4Z3. Tel: (514) 687-5010, Fax: (514) 686-5501

\section{Members at Large}

M. Claude Godbout

Doyen, Faculté de foresterie et de géomatique, Université Laval, Québec, QC, G1K 7P4. Tel: (418) 656-2116, Fax:
(418) 656-3177

\section{Mr. Paul Griss}

General Delivery, Canmore, AB, TOL 0M0. E-Mail: paul.griss@canrem.com.ca. Tel: (403) 678-9414,Fax: (403) 678-9414, Voice mail: (416) 926-9721, Cellular: (416) 704-0532

\section{Ex Officio}

Dr. Fred C. Pollett

Director General, Science \& Sustainable Development, Canadian Forest Service, Natural Resources Canada, 351 St. Joseph Blvd., Hull, QC, K1A 1G5. Tel: (819) 997-1107, Fax: (819) 994-7022

\section{Executive Secretary}

Dr. Mireille Brochu

4787 Massey Lane, Gloucester, ON, KIJ 8W8. Tel: (613) 746-9491, Fax: (613) 746-9491

\section{Appendix II. Terms of Reference}

\section{Introduction}

The Forest Research Advisory Council of Canada (FRACC) provides the Assistant Deputy Minister (ADM) of the Canadian Forest Service (CFS) with advice concerning the status, needs, and priorities of forest research and development in Canada, with particular reference to the R\&D programs conducted or financially supported by CFS.

The Council's goal is to assist the CFS in planning and executing a strong, effective, and well-focused forest R\&D program, at its own research establishments as well as through support and collaboration with other research agencies. Such a program is vital to enable the Canadian forest sector to practice sustainable development and remain internationally competitive, and to help ensure that Canadian society derives an optimum mix of benefits from the nation's forest resources.

\section{Functions}

The functions of FRACC are as follows:

1. Review and evaluate the research policies, strategies, and programs of CFS in relation to international, national, and sectoral needs and objectives, as enunciated in the National Forest Strategy, federal S\&T policy framework, international and federal-provincial agreements, and elsewhere.

2. Review and analyze the R\&D roles and responsibilities of CFS in relation to national and sectoral needs and the roles and capabilities of other forestry and research organizations.

3. Identify and analyze strategic $R \& D$ priorities for CFS that are compatible with the national and international responsibilities of the Service.

4. Review and assess the extent and effectiveness of CFS's leadership and coordination of, and participation in collaborative $R \& D$ programs with other forestry and/or research organizations.

5. Review and assess the nature and effectiveness of CFS's technology transfer activities and other forms of research communication and information exchange.
6. Examine the orientation and balance of the CFS R\&D program on a broadly regional basis, and establish ongoing liaison with regional/provincial/territorial forest research advisory bodies across Canada.

7. Conduct special studies, analyses, or workshops on strategic issues of opportunities affecting forest R\&D in Canada, as appropriate.

8. Make recommendations to the ADM-CFS on any or all of the above, either on the Council's own initiative or at the request of the ADM.

9. Prepare an annual report to the ADM-CFS (in a form suitable for subsequent publication and for consideration by CCFM as an information item), that:

- details the Council's activities and deliberations;

- provides an analysis of and/or updates strategic issues and priorities affecting forest R\&D in Canada;

- identifies actions that might be taken to address these issues on the part of forestry and/or research agencies; and

- presents recommendations on specific actions to be taken by CFS.

\section{Membership}

The Council shall comprise no fewer than 12 and no more than 14 members. Appointments will be made by the ADMCFS for periods of three years; members may be reappointed for a maximum of one additional three-year period. Appointment periods will be staggered so that continuity of Council activities can be maintained at all times. A Chairperson will be appointed by the ADM-CFS from among the members of the Council; this appointment will normally be for three years, but may be for a shorter or longer period at the discretion of the ADM. A Vice-Chairperson, to act on behalf of or in place of the Chairperson when necessary, will be selected by the members of the Council; the Vice-Chairperson will not necessarily succeed to the Chair. In addition, the Director General, Science and Sustainable Development Directorate, CFS, will be an exofficio member of the Council. 
Members will be selected on the basis of their personal experience, leadership, and skills, in particular as these relate to the conduct and management of research and the sustainable development of the forest sector. The selection process will bear in mind the need to maintain a balanced membership on Council in terms of regional representation and agency affiliation. As far as possible, Council membership will at all times include (but not necessarily be restricted to) representatives from industry, provincial governments, universities, other federal agencies, and non-government forestry and environmental organizations. However, no specific membership quotas will be set for these groups.

\section{Method of Operation}

The Council normally shall meet three times per year, at the call of the Chair. The Council will address topics that arise from, or are pertinent to, its functions as listed above, as well as other related issues that may emerge from time to time or that are referred to Council by the ADM-CFS. To assist in these activities, Council may establish ad hoc subcommittees and/or give specific assignments to its members. The Council will prepare an annual report to the ADM-CFS; this report will be in a form suitable for subsequent publication by CFS on behalf of the Council. The Chairperson and members of the Council will be assisted by a part-time Executive Secretary. Per diem and necessary expenses of the Executive Secretary will be paid by CFS on a contractual or similar basis. The duties of the Executive Secretary will be to prepare minutes of Council meetings, prepare draft versions of the annual report for approval by Council, confirm meeting arrangements, and provide other ongoing liaison and support for the Chairperson and Council with respect to FRACC business.

An annual budget will be provided to the Council by CFS to cover the costs of travel and other meeting expenses, printing of reports, and other related activities of Council and its subcommittees.

Revised October 1994

\section{Appendix III. Brief to Ministers regarding the Science and Technology Review}

Forestry Research Conseil consultatif

Advisory Council de la recherche

of Canada forestière du Canada

August 17, 1994

National Advisory Board on Science

and Technology (NABST)

c/o Dr. Jon Gerard

Secretary or State (Science, Research and Development)

11th Floor, East Tower

235 Queen Street

Ottawa, Ontario, K1A 0H5

\section{Dear Sir:}

I am writing to you as the president of the Forest Research Advisory Council of Canada (FRACC), Canada's only national advisory body focused exclusively on forest research, to make input to the federal government's Science and Technology Review.

\section{Forest Research Advisory Council of Canada}

The Forest Research Advisory Council of Canada has existed as an advisory body since 1983 . The mandate of the council is:

To provide the Assistant Deputy Minister of the Canadian Forest Service (CFS) with advice concerning the status, needs and priorities of forest research and development in Canada, with particular reference to the $R \& D$ programs conducted or financially supported by the CFS.

The Council's goal is to assist the CFS in planning and executing a strong, effective and well-focused forest R\&D program at its own research establishments as well as through support and collaboration with other research agencies. Such a program is vital to enable the Canadian forest sector to practice sustainable development and remain internationally competitive, and to help ensure that Canadian society derives an optimum mix of benefits from the nation's forest resources.

The Council identifies strategic research needs, objectives and priorities, promotes research coordination and the creation of R\&D partnerships, reviews ongoing $R \& D$ activities and makes recommendations to the ADM-CFS, in order to foster an effective and balanced response to national and international research needs.

The membership of the Council comprises no fewer than 12 and no more than 14 members. The membership is geographically dispersed across Canada and reflects the senior level practitioners in industry, provincial governments, universities, other federal agencies, and non-government forestry and environmental organizations involved in the conduct and management of research and sustainable development in the forest sector. Members serve a three-year term, with the Council meeting three to four times annually.

FRACC has an additional task. In 1987, the Canadian Council of Forest Ministers (CCFM) decided to establish forestry advisory groups in respective provinces or territories and asked FRACC to coordinate a Canada-wide overview of forestry research priorities and concerns. Forest research advisory groups now operate in most provinces and work with FRACC to prepare an annual review of research priorities which is presented by FRACC to the CCFM annually.

\section{The Importance of Forests and the Forest Sector in Canada}

By and large, the forest resources of Canada have provided the capital to begin building this nation. Our resources still play an enormously important role in our well being and must be carefully husbanded in light of their role as a source of economic stability, a source of ecological health, and for Canada 
as a nation, an important segment of our international responsibilities.

The character of the forest resource (species, age and areal extent) in Canada has largely determined the sector's competitive position in global forest products trade. The forest resources are largely under public ownership (90\%), and regulated private access to utilize these resources has been the hallmark of the forest "economy". For most of our history, this national patrimony has had a pervasive impact on our regional development and even today remains a key sector (either absolutely or relatively) for virtually every province. Forests cover nearly $50 \%$ of our landscape ( 416 million hectares) and represent $10 \%$ of the forests around the globe. No other developed country in the world has such a high degree of its forests under public ownership (approximately $80 \%$ by the provinces, $11 \%$ by the federal government and the balance - $9 \%$ - under private ownership). By way of comparison, the United States has approximately $70 \%$ under private ownership, $20 \%$ by the federal government and the remaining $10 \%$ by state and local governments.

Of the 416 million hectares of forest, nearly 27 million hectares are legally reserved as "heritage" forests where no commercial activity is permitted and another 24 million are considered "conservation" forest by public policy, in other words, only "protected" by de jure or de facto means. Commercial forests account for approximately 50\% of the total (209 million hectares) and only about $50 \%$ of this category (112 million hectares) are managed with timber production as the predominate goal of forest land use. However, it should be noted that while timber production may be the primary management focus on this category of land, a host of non-timber goods and services ranging from wildlife habitat to recreational opportunities are a complementary output to this apparently "single use" activity.

The economic benefits derived from forest utilization are both manifold and widely dispersed. About 350 communities depend largely on the forest sector and approximately 311000 persons are directly employed with an additional 466000 indirectly employed in associated activities (1993). The sector contributed 3.1\% to GDP in 1992 (or $\$ 18.7$ billion at factor cost). Exports were approximately $\$ 23$ billion in the same year and represented $15 \%$ of our total exports. Further, forest product exports contributed overwhelmingly to our merchandise trade balance. Regionally, nearly half the manufacturing sector in British Colombia and New Brunswick is represented by the forest sector and it is the second most important industry in Quebec.

Canada's forest industry presents significant opportunities for growth. Forecasted demand growth of selected products in North America, 1993-2000:

$\begin{array}{lcc}\text { Softwood Lumber } & + & 3 \% \\ \text { Softwood Plywood } & - & 19 \% \\ \text { Oriented Strand Board } & + & 116 \% \\ \text { Particleboard } & + & 46 \% \\ \text { Medium Density Fibreboard } & + & 145 \% \\ \text { Engineered Wood Products } & + & 300-400 \%\end{array}$

Source: RISI, June 1994.

While the market pulp sector is very cyclical and can be expected to fluctuate with the world economy, the cyclical upturn forecast in 1995-97 will benefit this segment of the industry.
Newsprint demand is anticipated to face minimal growth in North America but to escalate rapidly in Latin America and Asia as literacy rates increase, and to rise in Europe as Europe-wide advertising takes hold. Canada has traditionally been an exporter of newsprint and is well positioned to take advantage of the offshore increases in demand.

But it is not all dollars, jobs and export market strategy. Public sentiment is rapidly changing. The increased public attention to non-timber goods and services over the last decade or so has prompted action on several fronts. This action includes new federal, provincial and territorial laws, policies and programs and the establishment of round tables on the environment and the economy at the national and provincial levels. At the national level, this growing interest culminated in the development of a National Forest Strategy and a Canada Forest Accord in 1992. This level of accomplishment in being able to knit together a national belief in the importance of our forests for a variety of consumptive uses and non-consumptive uses is a first in the developed world. The Strategy and the Accord are endorsed by all levels of government, private industry and forest owners, Aboriginal Peoples, labour and academia and a diverse range of environmental groups and NGOs. This cooperative national effort to recognize society's changing perception of forest stewardship is under the guidance of the Canadian Council of Forest Ministers. Sustainable development of the forest resource for both consumptive and non-consumptive uses and values is the predominate theme of all these initiatives in Canada.

\section{The Need for Forestry Science and Technology}

The challenge of sustainable development is beyond the capacity of any single institution, private or public. However, our knowledge of forest ecosystem functioning and response to human intervention is far from complete, and Canada's forestry science and technology programs must be focused on these information gaps so that the challenges and opportunities of sustainable development can be successfully addressed.

Canada's forests and forest-based economy can continue to play a major role in sustaining our way of life and standard of living, but to do so will require that they undergo a continuous and dynamic process of change in response to internal needs and external pressures. External forces for change range from public pressure for more environmentally acceptable forest practices and products to the need to address international trade barriers. Within the forest sector, two principle driving forces for change are the need for the industry to remain economically viable in an increasingly competitive international market and the need to preserve the biodiversity and productive potential of Canada's forest resources for a variety of traditional and non-traditional values and current and future end uses. Developing and applying holistic forest management that is economically, environmentally and socially sustainable at a forest ecosystem or landscape level is exceedingly complex. Our current state of knowledge allows for a start in the process but considerably more research and development must be devoted to such aspects as biological ecosystem functioning, forest health monitoring, environmentally benign ways of intervening in the forest, and techniques for integrating all this information in ways that can be used by the forest managers. Examples of leading science and technology that are only now beginning to be applied include biological control of pests, plant biotechnology, integrated fire, pest, and forest 
management systems, remote sensing, GIS and other monitoring and analysis techniques, decision support systems development, biodiversity and resource conservation, and integration of wildlife, recreation and other non-consumptive values.

The principles of sustainable development are international in scope and are now beginning to impact globally. Canada has positioned itself well, by taking the stance domestically that new forms of partnerships and collaboration are not only desirable, but necessary. This complex of interrelated responsibilities led, first in 1987 and again in 1992, to the development of forest sector strategies to which all major stakeholders pledge their support. The 1992 National Forest Strategy and its companion Canada Forest Accord are based on sustainable development concepts and set out an array of actions, in topics ranging from forest management practices to research and Canada's international responsibilities, to which each participating organization is committed.

At the same time, Canada has taken a lead role in the coordination of efforts with the development of international conventions and agreements impacting on the forest sector. Global leadership was manifest in Canada's pursuit of an International Forestry Convention leading up to the Earth Summit in Rio in 1992. The prominence of forests in Agenda 21 and the Forest Principles have advanced the global forest dialogue to unprecedented international attention. The creation of national and international Model Forests and the development of criteria and indicators for measurements of progress in sustainable forest management are two more examples of global leadership.

I hope that I have left you with the very strong message that we have done a lot and can consequently be proud. I trust that you will also believe that there remains a great deal to do at home so that we can continue to improve our domestic operations while taking a commanding global position with respect to our forest and their relationship to those of the world.

\section{The Role of the Federal Government in Forestry Science and Technology}

The question now becomes one of whether or not there is a role for the federal government in science and technology (S\&T). My answer is yes.

To quote from the report of the Committee on Federal Science and Technology Priorities, Phase II:

S\&T activity is not an end in itself. It is a means to achieve particular objectives such as the advancement of knowledge, the accomplishment of departmental missions, and so on. There is thus a natural and reasonable tendency to view S\&T simply as tools to be applied to achieve a purpose. However, the tools themselves, their condition and the way they are applied can be critical to the attainment of objectives.

Such is the case here. Canada needs a strong and competent research capability in forestry $R \& D$ in light of the undeniable fact that few of the provinces have significant research establishments devoted to forestry. Additionally, some of the required research is too long term (or basic) to be taken up by the private sector. Another significant fact is that the required level of coordination and cooperation across the country can be successfully accomplished only at a national level. And it must be done full time as well as consistently. I invite your comparison of what is required with what is now in place.

The Canadian Forest Service (of Natural Resources Canada) is the federal government's lead agency for forestry matters and is the single largest forestry research and development organization in the country. Its in-house program addresses research and it is the only truly national program in Canada that focuses on that field. The CFS should continue to have a lead responsibility for national and international aspects of forestry research and development, especially in the areas of forest resources and forest management, and to work with other research and development performers to ensure that the wider implications of those other agencies' activities are adequately recognized and factored into national and international research and development programs. The five major forestry S\&T objectives identified by CFS for the period 1995-2000 are:

- Understanding the fundamental processes, functions and dynamics of Canada's forest ecosystems.

- Providing national and international leadership in forest ecosystem monitoring, data collection and analysis.

- Developing and promoting better ways for protecting and enhancing the health, diversity and productivity of Canada's forest ecosystems.

- Developing the integrated knowledge, tools and techniques required for the implementation of holistic and sustainable management of forest ecosystems.

- Contributing to the future viability and competitiveness of Canada's forest-based economies.

The Canadian Forest Service not only undertakes, but also coordinates, forestry R\&D activities and it is thus most important that it retain an active role in all regions of the country. As a result of close and effective inter-agency working relationships that have been developed across the forest sector during the past several years, there is now, in general, a highly effective division of R\&D and associated operational program responsibilities among agencies, that avoids serious duplication or overlap and ensures that each agency is able to contribute to the total forest sector S\&T needs. In much abbreviated form, the key R\&D roles of the other types of agencies that collaborate with the CFS can be characterized as follows:

- Provinces: conduct and use of applied forestry R\&D linked to operational programs plus associated extension and development work.

- Cooperative Industrial Forestry R\&D Organizations (FERIC, FORINTEK, PAPRICAN): conduct of applied, generic $R \& D$ of interest to wide client base in forestry operations and manufacturing.

- Forest-based Manufacturing and Service Companies: conduct of proprietary R\&D in forest products or other forestrelated technologies and services, and funders and users of more generic $R \& D$ related to forest management and utilization.

- Universities (Forestry and Other Faculties): conduct of basic and applied R\&D that may involve specialized and indepth expertise linked to undergraduate and graduate programs.

- Forestry R\&D Advisory Bodies: provision of advice on $R \& D$ priorities and assistance in promoting inter-agency research coordination and collaboration. 
- Other Federal Departments and Agencies: funding and/or conduct of some forestry related R\&D of relevance to their particular mandates (includes other sectors of Natural Resources Canada, Department of the Environment, NABST, Agriculture Canada, National Research Council, National Science and Engineering Research Council, and Social Sciences and Humanities Research Council).

Is it adequate? No. But the framework is now in place and output can be effectively leveraged through additional funding coupled with stringent monitoring controls to ensure efficacy and relevance. Funding does need to be increased in light of the fact Canada spends only about 0.8 per cent of its forest products sales on forest related research compared to between 1.5 and 1.7 per cent of our competitors such as Scandinavia and the United States.

\section{Summary}

The facts of the matter are very straightforward. Canadians have a forest ethic. Our National Forest Accord conclusively shows we intrinsically understand that we need our forests to continue our standard of living (in both an aesthetic and an economic sense) in this country. Equally well understood but less well articulated is the fact that we have an unprecedent- ed opportunity to increase our national wealth by investing more heavily in the proper care and management of our heritage.

Science and technology are the correct tools to accomplish this, for it is only through the application of science that we will be able to diminish the emotion we all feel for our forests. Only then can we continue the meaningful debate about the correct role of our forests in safeguarding ecological integrity; increasing jobs; promoting regional economic stability; and supporting Canada's role in the world as a respected and influential nation.

The Forest Research Advisory Council of Canada strongly recommends that the Government of Canada, and more particularly, the Canadian Forest Service of Natural Resources Canada, have both a strong and clear mandate and adequate funding to play a key role in the development and national coordination of S\&T as it relates to the national forestry sector. Further, it recommends that the role of S\&T at a federal level be given greater prominence than it currently has relative to other national programs.

Yours truly,

Michael R. Innes

President

Forest Research Advisory Council of Canada

\section{Appendix IV. Workshop on Landscape Management Ottawa, November 23-24, 1994 Summary of Presentations ${ }^{1}$}

\section{Introduction}

This workshop was convened by the Forestry Research Advisory Council of Canada (FRACC) to provide the members of FRACC with up-to-date information on ongoing research in the emerging area of landscape management.

Members of FRACC, representatives from provincial research councils and senior staff from the Canadian Forestry Service were in attendance.

The workshop was chaired by the Chair of FRACC, Mr. Michael R. Innes of Abitibi Price.

Dr. Ole Hendrikson, Coordinator, Environmental Impacts, Canadian Forestry Service, who had been instrumental in the selection of speakers, set the tone for discussion by stressing that scientific understanding of land resource systems was absolutely essential to modern forest management.

\section{Landscape Management in the Fundy Model Forest}

\section{Dr. Louis LaPierre, Université de Moncton}

Dr. LaPierre is the holder of the K.C. Irving Chair in Sustainable Development at the Universite de Moncton. A Professor of Ecology at Moncton since 1970, he also headed the Environmental Science Research Centre from 1990 to 1994. He is Chair of the Fundy Model Forest.

\section{Presentation}

The Fundy Model Forest is one of 10 forests so identified. The intention is to develop an integrated management plan, covering all uses and users. As a result, there are many stakeholders

'The text and/or visual material for some the presentations are available from the Canadian Forest Service (819) 997-1107 ext. 2001. with diverse agendas, from recreational users to the forest industry. The process builds on consensus.

The Fundy Model Forest has an area of 420000 hectares (1.4 million acres), a population of 35000 . There are three mills in the Forest (two lumber, one pulp and paper). Ownership is $60 \%$ private, the rest is parkland. Twenty-six partners are involved in the management structure. Public interest is high. A forum on landscape management attracted 90 persons.

Among the numerous issues that have to be taken into account in the development of an integrated management plan are:

Scientific issues: economics, ecological patterns and processes, biodiversity, indicators of sustainability, population dynamics, natural succession, climate, etc. On the latter topic, it is worth noting that a $0.3^{\circ}$ change causes stress on a black spruce economy. Twenty-seven graduate students are currently involved.

Forest management issues: examples include road building, clearcutting, forest fires.

Social aspects: for example, in part of the Forest close to urban centres, city dwellers want to have input in the planning process, and their perspective is different from that of their rural neighbors.

So many considerations have to be taken into account that it was decided that it would be more practical to study smaller areas. Therefore, a decision has been made to develop integrated plans not for the Forest as whole, but by parcels of 200 to 4500 hectares. It was felt that the scale chosen would permit extrapolation. 
The importance of coordinating landscape flow and forest management was stressed. This points out the influence of research on the operational aspects of model forests and is important ultimately, insofar as model forests have the potential to influence forest policy elsewhere.

In conclusion, the major lesson learned from the process is that communication is important and that consensus building is the secret. Partners have to be empowered.

\section{Discussion}

Members of FRACC commented on the importance of the human aspect and of the need to foster relationships and to build trust among the partners.

On the economic side, decision support tools are needed.

Members of FRACC were most impressed with the work accomplished to date in the Fundy Model Forest.

Primary environmental regimes as a basis for the spatial modelling of ecosystems at local, regional and national levels

\section{Dr. Richard Sims, Canadian Forest Service, Sault Ste-Marie}

Dr. Sims has an interdisciplinary background, with degrees in forestry, soil science and remote sensing. He has been with the Canadian Forest Service for 18 years.

\section{Presentation}

Although the concept of ecosystem management is still not well defined, Canada has no choice but to take an integrated approach. The message and vision from the Rio Summit are clear: conservation and biodiversity are key values.

The research reported here looks at the impediments to implementing ecosystem management from a scientific point of view (as complementary to political, economic and social aspects). What are the building blocks of an ecosystem? Can models be developed to predict the effects of human intervention?

Impediments include the lack of analytical framework, inadequate resource survey methods, poorly quantified habitat definition and mapping, poor understanding of genetic diversity, need for spatial extension of biological site data, poor understanding of genetic diversity, need to account for system dynamics. Paradoxically, another factor is the explosion of scientific information. Thousands and thousands of papers are published every week, and keeping up with information means that researchers become more and more specialized.

The study area for the research is a $900-\mathrm{km}^{2}$ portion of northern Ontario. An ecosystem classification was developed, which is found useful by field foresters. It provides information on soil, vegetation and wildlife for 3500 plots. A portable global positioning system is used. This is a joint effort by CFS and the Ontario Ministry of Natural Resources. Several other provinces are also using a plot system for ecosystem classification.

Primary environmental regimes of elevation, climate and soil are combined within a hydrologically sound digital elevation model. In the future, biological reference data (biosurveys, ecosurveys) will be added. This model has many operational applications. Forest cover under various scenarios can be predicted. It can produce a topographic wetness index that indicates areas skidder operators should avoid, to maintain drainage patterns and productivity. Information can be transferred to maps and help provide a basis for ecosystem management. Colleagues in Ontario and Australia are collaborating in this research.

\section{Discussion}

In the ensuing question period, a FRACC member commented that it would be interesting to digitize historical fire information to predict the effects of disturbance, or to predict forthcoming insect infestations. The inclusion of real time data would be useful.

The Chair commented that new and better decision tools were no doubt useful, but how can we be convinced that action taken using these predictive tools will not be destroying what we want to protect? Dr. Sims replied that research proceeds in an incremental fashion: as more and more information is available, as analytical tools become more refined, more parameters can be included, and decisions can be made with more confidence. However, the fact remains that forestry is active experimentation, and that constant correction and adjustment are required as the knowledge base increases. We have to do the best we can with the available information. Trade-offs are necessary.

\section{Landscape management perspectives and production of "usable" research}

Dr. Louis Bélanger, Université Laval

Dr. Bélanger describes himself as a biologist turned forest engineer. He is a professor in the Département des sciences du bois et de la forêt, Faculté de foresterie et géomatique, Université Laval.

\section{Presentation}

The theme of the presentation is usable research. This occurs when teams of researchers and users interact. The Model Forest described in Dr. Lapierre's presentation is an excellent example of usable research.

Forest managers are frustrated with research. There is a vast amount of knowledge, but it is disjointed, disciplinary, not integrated. Synthesis and integration are needed. Public input is necessary.

The priority of the research is to develop workable formulae for reconciling economic needs with the new and changing environmental and social demands. An example is the outcry with respect to clearcutting. Individual cut size tends to be emphasized by the opponents of clearcutting, whereas the percentage of landscape harvested is the major issue for sustainability. Therefore, for clearcutting to become acceptable, landscape management concepts have to be introduced.

Research at the landscape level existed before (e.g. moose management, water management); what is new is integration at the ecosystem level, and the concept of integrated (multiple use) forest management. Different ways to define the desired landscape condition include regulation ("minimally acceptable landscape"), emulating natural disturbance regimes, setting management objectives (including biodiversity) for culturally modified landscapes where it is not necessary to emulate nature, and modelling for "optimized landscape management" (if this is really possible). Management-centred and ecosystem-centred research are complementary strategies. Managementcentred research responds to public demand, and generates sustainable management indicators.

The size of management units is of critical importance. A region is too large, a stand is too small. A landscape can vary between 50 and $500 \mathrm{~km}^{2}$. The choice must be based on a number of criteria such as spatial conditions, nature of the ecozone (hardwood, mixed, spruce) biodiversity, wildlife, natur- 
al disturbances, but it must also include people values (visual impact, hunting, watersheds, etc.). A challenge is to find a unit that people will relate to culturally, such as the concept of "terroir" in France.

Once the area is delimited, research priorities must be selected in consultation with stakeholders, and must relate to management problems. If the users are involved from the beginning, the results will be usable. Model forests are a very useful tool, as they enable landscape level experiments: propose a landscape model as a working hypothesis, field test the landscape model, conduct research to address questions raised by one model and adapt the model landscape with the new knowledge. Landscape management will always be an adaptive process. At any given time, knowledge is limited and social needs are always changing.

\section{Discussion}

The need for criteria and indicators of sustainable management was discussed: how do you prove that clearcutting mimics nature? How do you prove that practices are sustainable management practices? What research is needed to help devise workable certification processes? Among the activities mentioned were: baseline studies, reaction of key species, comparative studies with natural forests, impact models. The speaker stressed the importance of working with units of reasonable size rather than with a whole region. Members commented that models that mimic nature were often mentioned, but they mimic nature at what point in time? When is the natural environment in equilibrium? But ecosystems are not in a steady state. Surely, one does not wish to reproduce catastrophes such as insect infestations; yet, mimicking fire disturbance regimes makes sense, as does using models to predict the effects of insect infestation. All in all, it was agreed that common sense should prevail: in some cases, it is wiser not to imitate nature.

The Chair thanked the speaker and commented on the need to involve the public in defining landscape priorities.

\section{How are landscape ecology and management changing forestry? \\ Dr. Steven Garman, Oregon State University \\ Dr. Garman's background is in wildlife ecology. His current areas of interest are landscape ecology and management. He joined the Department of Forest Science, University of Oregon, four years ago. Prior to that, he was a member of the faculty at the University of New Hampshire.}

\section{Presentation}

Ecosystem management is the integration of ecologic, economic and social principles to manage systems in a manner that safeguards ecological sustainability, diversity and productivity of the landscape. Implementation and planning must integrate social values. The best mathematical models may never be implemented otherwise, and may be challenged in court.

The implementation and planning process is as follows:

Data

collection (remote sensing or other survey tools)

Modelling (spatial data, changes over time, recognition of time and space hierarchy of landscape, historical range of variability, scaling up)
Assessment (changes predicted and analyzed, management scenarios developed, integrating ecological, economic and social principles)

Decisions (pros and cons are balanced).

This research is detailed in a report prepared by Dr. Garman and colleagues from the USDFA Forest Service. The draft final report, dated October 1994, is entitled: Research Problem Analysis - Modelling, Monitoring and Displaying Ecological Change at Watershed to Landscape Levels: Tools for Ecosystem Management.

Lessons for science can be drawn from the conservation of the spotted owl habitat in Oregon. The importance of building consensus and of including all stakeholders cannot be over-stressed. Decisions cannot be based on science alone. Science provides the sophisticated information which affects the planning process. More research is needed in policy analysis and planning. Scientific data have to be simplified; the details have to be used to develop analytical approaches. Decisions cannot be based solely on empirical data. In any event, there are no or few empirical data in most instances: models have to be adapted as new knowledge is acquired.

It is very important to decide the best way to represent information. People tend to be interested in smaller sized areas, minimal size spatial units. There are different methods of scaling up information. This is a hot topic and could be the basis for another seminar.

\section{Discussion}

Members noted that a major difference between the USA and Canada is that any decision in the USA can be (and generally is) challenged in court. Members briefly discussed the social and economic consequences of shutting down a major industry, as occurred in Oregon. Economic restructuring appears to be successful and unemployment is down, thanks to new high-tech industries and knowledgeable workers (although unskilled workers suffered; many probably moved out of the State). Members noted that, unfortunately, such recovery had not followed the collapse of the fishing industry in Newfoundland.

\section{Landscape management in British Columbia Dr. Richard Page, British Columbia Ministry of Forests Dr. Page is a biologist by training.}

\section{Presentation}

Dr. Page reviewed the process for the development of the Forest Practices Code in British Columbia. He concurred with previous speakers that the thing not to do was to put scientists in a room, have them propose a plan and adopt it. The community has to be involved.

British Columbia learned that lesson the hard way. The preservation of the province's old-growth forest (as highlighted in the Clayoquot Sound publicity) has become a global issue.

The landscape scale is a good one for research on biodiversity, in the sense that species do not confine themselves to a stand. Habitat assessment is a case in point. Research in the field helps pinpoint differences in elevation for winter and summer ranges; models can be developed and decisions can be made on how much to preserve for winter habitats. This works for 
one species, and for species-by-species studies. For biodiversity, information is required on "community of species". Inventories are required (and new species are found as the canopy is explored), as well as information on natural disturbance regimes, old forests and impact of forestry (shapes of reserves, buffers, minimizing fragmentation).

A Commission on Resources and Environment held hearings in communities. Scientists had to explain the issues to the public in simple terms. Some of the information was digitized and presented on microcomputers (workstations). People in the room could see the effects of various scenarios.

The population is not of one mind with respect to forest management: to many, jobs are the most important concern, and they do not see why others care about birds or other animals.

The Forest Practices Code includes guidelines for managing for biodiversity, including mimicking natural disturbance regimes and, recommendations for age class and size distribution (mixture of species at the landscape scale). The guidelines will be refined as new research results become available.

The Forest Practices Code could not have been developed without the long-term research that has taken place in British Columbia in the last decades.

\section{Discussion}

The question of mimicking natural disturbances rose again, with Dr. Page reassuring the audience that British Columbia will not try to mimic hurricanes or insect epidemics.

The importance of adaptive management was stressed: decisions are made on the basis of incomplete information and adjustments are made as more accurate information becomes available. Moving in the right direction is the best way to go for managers, knowing that they may not see the effects dur- ing their lifetime.

\section{Conclusion}

After thanking the members for their excellent presentations, the Chair concluded by asking members to list issues they identified as a result of the workshop. The resulting list follows:

- Importance of people dimension and of public information (public forums are a functional means of identifying priorities).

- Need for adaptive management as the needs of society and ecosystem functioning are more precisely defined.

- Decisions need to be made on which models to adopt as being most useful to shed light on ecosystem functioning.

- Research as a tool for forest managers.

- Importance of long-term experiments such as model forests to provide multidisciplinary input within a framework people are able to relate to.

- Finding the right balance between short-term (e.g. helping managers) and long-term (e.g. model forests, fundamental research) considerations.

- Information overload is now a real problem; there is a need for better management and use of information.

In closing, members commented that they found the workshop very useful as a means of obtaining a comprehensive overview of a complex topic with national and international ramifications. 